\title{
Searching for Appropriate Ways to Face the Challenges of Complexity and Dynamics
}

\author{
Peter Sommerfeld * and Lea Hollenstein
}

Peter Sommerfeld is professor of Social Work at the University of Applied Sciences Northwestern Switzerland, School of Social Work. Recent research has been completed in the fields of probation services, psychiatry and occupational social work. He teaches theories of Social Work and General Systems Theory. He is co-president of the Swiss Society for Social Work. Lea Hollenstein is senior researcher at the institute for 'Social Work Research and Cooperative Knowledge Creation' at the University of Applied Sciences Northwestern Switzerland, School of Social Work. Recent research has been completed on integration and exclusion processes and in the field of psychiatry. She teaches on professional assistance to female victims of violence.

*Correspondence to Professor Dr Peter Sommerfeld, Institute for Social Work and Health, Riggenbachstrasse 16, CH-4600 Olten, Switzerland. E-mail.peter.sommerfeld@fhnw.ch

\begin{abstract}
People, as bio-psychological systems, are just as dynamic and complex as the social systems that they create. Social work intervenes in the interplay of these two complex, dynamic systems. How can we capture these complexities and dynamics in social work research and practice? The paper introduces the theoretical grounds on which a mixed-methods design has been developed combining a longitudinal quantitative method called Real Time Monitoring that produces dense time series data with qualitative methods (biographical and reflecting interviews) within the framework of grounded theory. After some short notes on the methodology, its application is demonstrated alongside a case example. Because complexity and dynamics challenge not only research, but also the practice of social work, the approach is finally discussed in view of the 'realistic evaluation' paradigm.
\end{abstract}

Keywords: Social work research, mixed methods, longitudinal design, systems theory, violence against women

Accepted: March 2011 


\section{Introduction}

'Social work interventions usually take place at the interface of the individual and social, where multiple factors and influences are continually at work' (Kazi, 2003, p. 803). This is the opening sentence of an article by Kazi (2003), who argues for the 'realist evaluation' paradigm. With this approach, Kazi and others (e.g. Pawson and Tilley, 1997) try to address the complexities deriving from the fact that human beings live their lives socially and that this sometimes creates problems requiring help and intervention. Because individuals themselves can be seen as complex systems on a micro level, which create complex social systems on a macro level, and because these two system levels are interrelated in a dynamic way, the problems that social work deals with are highly complex and-here, we go a step further than Kazi-highly dynamic. How can we capture these complexities and dynamics in research and practice in order to better understand these problems and to hopefully improve those social work interventions designed to help? Finding an answer to these questions is without doubt a decisive challenge for both research and practice in social work. In this paper, we want to introduce the way in which we have tried to face these questions and present what we developed in doing so. In the first section, we introduce some theoretical concepts that stood at the start of our method development and that we used in our attempt to capture conceptually the real complexity and dynamics of the human way of life. In the second section, we present in brief our chosen mix of methods (Greene et al., 2010). In the third section, we present case material to illustrate the use and yields of our methodological approach. A discussion closes the paper in section four.

\section{Human life and the theory of self-organisation}

Norbert Elias (1978) bases on the fact that a person never exists and acts as an isolated being but instead is always oriented towards and dependent on other people. The central concept that we take from Elias is 'social figuration'. With their whole persons and 'the totality of their dealings in their relationships with each other' (Elias, 1978, p. 130), people as social beings form necessarily changing interdependencies, or social figurations, such as families, schools, cities, social classes or countries, to lead their lives. The term 'social figuration' pointedly puts in a nutshell the social nature of human conduct of life and the direct simultaneity of social and individual. In their structure and dynamics, social figurations can be distinguished from the personality structure of the individual person, but they are very tightly meshed with personal development:

Human beings form figurations. The way that people live together in groups, small and large, is in a certain way unique. It is always codetermined 
by the transmission of knowledge, or by the entry of the individual into the specific symbol world of an already existing figuration of people .... The young person's growing integration into human figurations as a process and experience and thus also the learning of a particular schema of selfregulation in dealing with other people is an essential requirement of personal development. A person's socialization and individualization are therefore different names for the same process (Elias, 1995, pp. 75 et seq., freely translated from the German).

The second concept that was important for the development of the methodology and that should be explained is the concept of Lebensführungssystem (life conduct system). The concept describes the same basic idea as Elias's social figuration, but, here, the perspective is such that the socially figured human form of life can be operationalised starting from the individual. This is just as significant for research methodology as it is for the practice of social work, which usually works with individual clients. With this concept, we refer to a paper by Bourgett and Brülle (2000). Following them, human beings secure their survival by forming life conduct systems (social figurations). Human beings as biological systems (the psyche is seen as a part of the biological system) form socio-cultural systems together with others of the same species to secure their survival as individuals and as a species, and they do so in the form of conducting their lives, which is an active, creative form of ensuring survival. But this active conduct of life at the same time remains embedded in the already existing social systems and the order and life conditions they define. Thus, a person's conduct of life is characterised by the dynamic interaction between the person and the social action systems (such as family, factory, school, probation service) that people create in order to live and survive. Concrete action systems are thus one side of a life conduct system and the socio-biological system 'human being' is the other. The two sides are connected via meaningful interaction, that is, social actions, including symbol-based communication: the interaction of psycho-social processes on the basis of bio-psychological processes on the part of the person with socio-cultural processes in social action systems is structurally connected. The two spheres are each prerequisite to each other and have a dynamic effect on each other. Psyche and sociality form an integrated whole in their difference. This changes the focus of research. The question is no longer about what environment is and what the individual is. Instead, the questions are now: How does the life conduct system of a particular individual work? What dynamics can we observe within it? And how are functioning, structure and current dynamics of this particular life conduct system connected?

If people's way of life can generally be accurately described with this theoretical approach, then the next question concerns how it is that, in this complex interplay, stable psychological and social structures develop, or how such life conduct systems are formed concretely. How does the social order of figurations arise and how does the psychological order arise with 
which individuals in this social order interact with each other? Here, it is our opinion that the theory of self-organisation of complex dynamic systems ('synergetics') has the most to say. This transdisciplinary approach describes and explains the spontaneous evolution of spatio-temporal and/or informational patterns in systems by the non-linear interactions between their components or modular subsystems (Haken, 1990; Haken and Schiepek, 2006). The following elements of this knowledge base are of particual importance for the development of the research design, because they show a path to reduce complexity in an appropriate way:

- $\quad$ self-organising systems produce coherent behavioural patterns ('Gestalts') instead of atomistic behavioural elements;

- these patterns are characterised by more or less complex dynamics, which can be described by some appropriate order parameters or macroscopic variables;

- dynamic patterns are more or less stable and there are often discontinuous transitions between these patterns (order to order transitions);

- discontinuous transitions are often prepared and accompanied by critical fluctuations and instabilities of the system's behaviour.

The core idea of the theory is that complex dynamic systems form themselves through the structural principle of 'circular causality'. The principle of circular causality describes the empirically well-established observation that order-forming processes start up when elements enter into interaction, due to whatever framework conditions or environmental conditions, and then the movement or activity of the parts becomes synchronised. The relative macro pattern therefore emerges from the activity of the parts and, conversely, the special form of synchronised activity of the parts at the relative micro level materialises through the structuring power of the order pattern at the relative macro level. The special quality of order formation of human conduct of life is that, whereas - as in all systems - the forming of patterns at the level of the concrete social action systems synchronises the activity of the parts, a further instance of action control comes into play, namely the human brain, which itself is a highly complex dynamic system that forms itself in action, in active dealings with and in the socio-cultural systems. What we have here, therefore, is double, synchronised creation of order of the psychological and social systems.

In our view, the macro social order in various social figurations emerges out of micro interactions among individuals and, in turn, orders or 'enslaves' individual action and the corresponding psychic development in a process called 'integration of the social systems'. The process of production and reproduction of social order is done by 'integrating individuals into the system', into defined positions within the interactional patterns that constitute the social order. Figure 1 shows the connection that interests us, namely that, at the same time as the individual becomes integrated into 


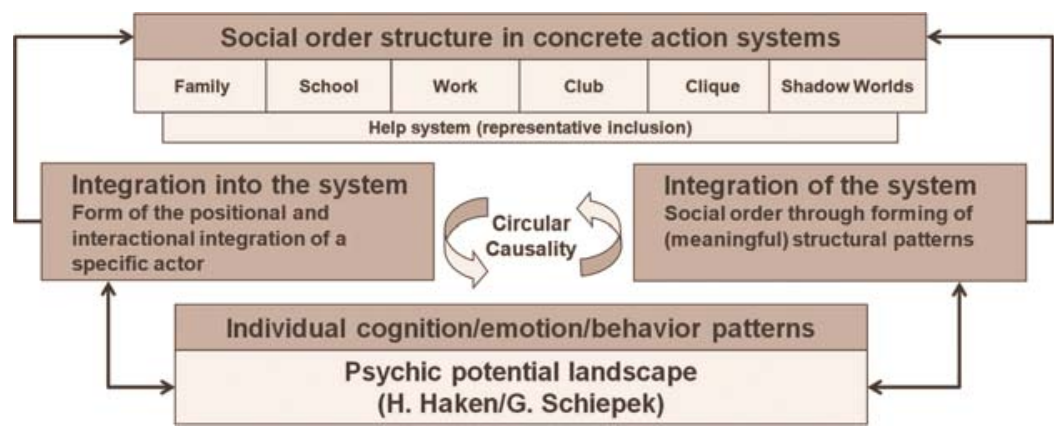

Figure 1 System levels

diverse social systems through the life course, the inner order structure of the individual is forming. This inner order structure, which, in turn, organises the neuronal activity in patterns according to the same principle of selforganisation, we call the 'psychic potential landscape', again following Haken and Schiepek (2006, pp. 138 et seq.). This contains a set of individual cognition/emotion/behaviour patterns, with which the actors lead their lives in the social systems. The specific, circular causal interplay between these two levels is each individual's life conduct system.

\section{On method}

The methodological challenge thus consists of reconstructing the life conduct system of a person in its fundamental patterns and current dynamics. For this reason, a guiding consideration when developing the methods was that we needed an instrument that can capture the current dynamics and an instrument that can capture the structural patterns of the life conduct system. These structural patterns emerge, as outlined theoretically above, in a lifelong, self-organising process of the conduct of life in social figurations. Thus, biographical interviews could be used to reconstruct the structural patterns. This method of data collection is sufficiently well known (see, e.g. Völter et al., 2009). Biographical interviews provide us with the data material for reconstructing the coming into being of the life conduct system. The second instrument is real-time monitoring (RTM) for the assessment of current dynamics, which will be described more fully below. We call the third instrument 'reflecting interviews'. These are semistructured interviews in the tradition of Jean Piaget that contain elements of non-directive therapy methods (De Shazer, 1991). The 'reflecting interviews' as we developed them are a longitudinal, qualitative method. All participants were interviewed every two months during a one-year period. Interview participants were first asked to reflect on their lives over the past two months in a narrative way. Then, they were asked to review and 
analyse the RTM data they had produced during the preceding two months by reflecting on the significant peaks in those data. Additionally, we asked them questions derived from our analysis of the RTM data and their biographical interview. By doing so, we had a very good instrument at hand to verify our hypotheses on the relevant patterns and the current dynamics as well as to deepen our understanding of the individual life conduct system. For all our analytical work, we chose the framework of grounded theory (Strauss and Corbin, 1990), which combines respect for contextual meanings with analysis of systematic regularities. However, we analysed each case separately up to the point of theoretical saturation, with the aim to learn to know a person's life conduct system in detail and to identify the central patterns in it. Using the analytical framework of grounded theory, the information obtained using the different instruments could be integrated.

To record the dynamics of psychological and social processes-because we are interested in the dynamic interplay of these two dimensions of a life conduct system - a longitudinal design with a frequency that is appropriate for the processes is required. Real-time monitoring (RTM), developed in psychology by Schiepek et al. (2003), provides this kind of suitably dense time-series data. Specifically, this means that participants fill out an internet-based standardised questionnaire every day, by computer or mobile phone. The data - in sum, up to 360 measures on each itemare transferred to our server via the internet as soon as the daily rating is finished. Repeated measurement procedures result in signals mirroring the dynamic activity of the system under consideration (in our case, the client within his/her life conduct system). In our different research projects, we focused on different social rehabilitation and reintegration processes in different fields of social work. Based on the literature on these processes (especially the U.S. national research project on recovery measures recovery approach, Onken et al., 2002, Dumont et al., 2005) and on an existing RTM questionnaire developed for psychosomatic therapy (Schiepek et al., 2003), we developed a basic questionnaire, with twenty-three items, on the following dimensions: hope/meaning, self (self-reliance/selfefficacy), change/progress, physical and mental well-being, emotions and (quality of) social relations. The questionnaire for the project from which we will present data below has since been modified and enlarged to include thirty-three items, including some specific items derived from traumatology (Fischer and Riedesser, 2003), because this project focuses on victims of domestic violence. Intensities are rated on a seven-step Likert scale. The participants need only about ten to fifteen minutes to answer the questions and it works like a standardised diary. Additionally, they can write in their own comments on any item that they wish. As will be shown below, information can be extracted from the raw data of the timeseries directly. For example, changes on the self-efficacy item, a general increase or decrease over most items, somatic disorders, an increase in 
emotionality and so on indicate dynamic processes and can be interpreted as such and reflected upon with the participants during the reflecting interviews. Patterns can be identified by correlating various items pointing in a same or contradictory direction.

Aditionally, the instrument and the corresponding analyzing method allow detection of phases of 'critical instability'. Following the theory of self-organisation, the dynamics are more intense in time periods of critical instability than in other phases. During a phase of critical instability, the contrasts are somehow sharper. Therefore, a method had to be developed in order to differentiate between 'normal' and 'critical' fluctuations. For this purpose, the number of direction reversals in the raw data and the amplitude of those reversals were assessed as indicators of the intensity of the time-series patterns. These so-called 'complexity measures' are calculated at the usual 0.05 and 0.01 significance levels (for a more detailed description of the calculation, see Sommerfeld et al., 2005, pp. 211-12; Schiepek et al., 2003, pp. 235-72). These significant complexity measures can be put into a diagram (the so-called 'complexity-resonance-diagram') in order to get an overview of the process as a whole as far as they are represented by the items of the questionnaire (see Figure 2 at the top for an example). By this means, phases of critical instability of the system's dynamics become visible.

\section{Data-based reconstruction of the dynamics and structural patterns of human life conduct systems}

In the following, three case examples will be presented to explain the method mix for capturing the dynamics and structural patterns in people's life conduct systems. The case examples are taken from a research project on the possibilities and limits of counselling women victims of violence that was supported by the Swiss National Science Foundation.

\section{Ursula Vogel \\ A rough case description}

Ursula Vogel (all personal data have been completely anonymised) immigrated to Switzerland from Venzuela eighteen years ago. In her last marriage, she was the victim of domestic violence, sustaining, among other things, a deliberately caused whiplash injury. As a consequence of the injury, she lost her job due to limited capacity for work. She reports having the following symptoms: headaches occurring unpredictably, neck pain, difficulties concentrating and sleeping, depression and symptoms of post-traumatic stress disorder (mainly dissociation). Six years ago, Ursula 


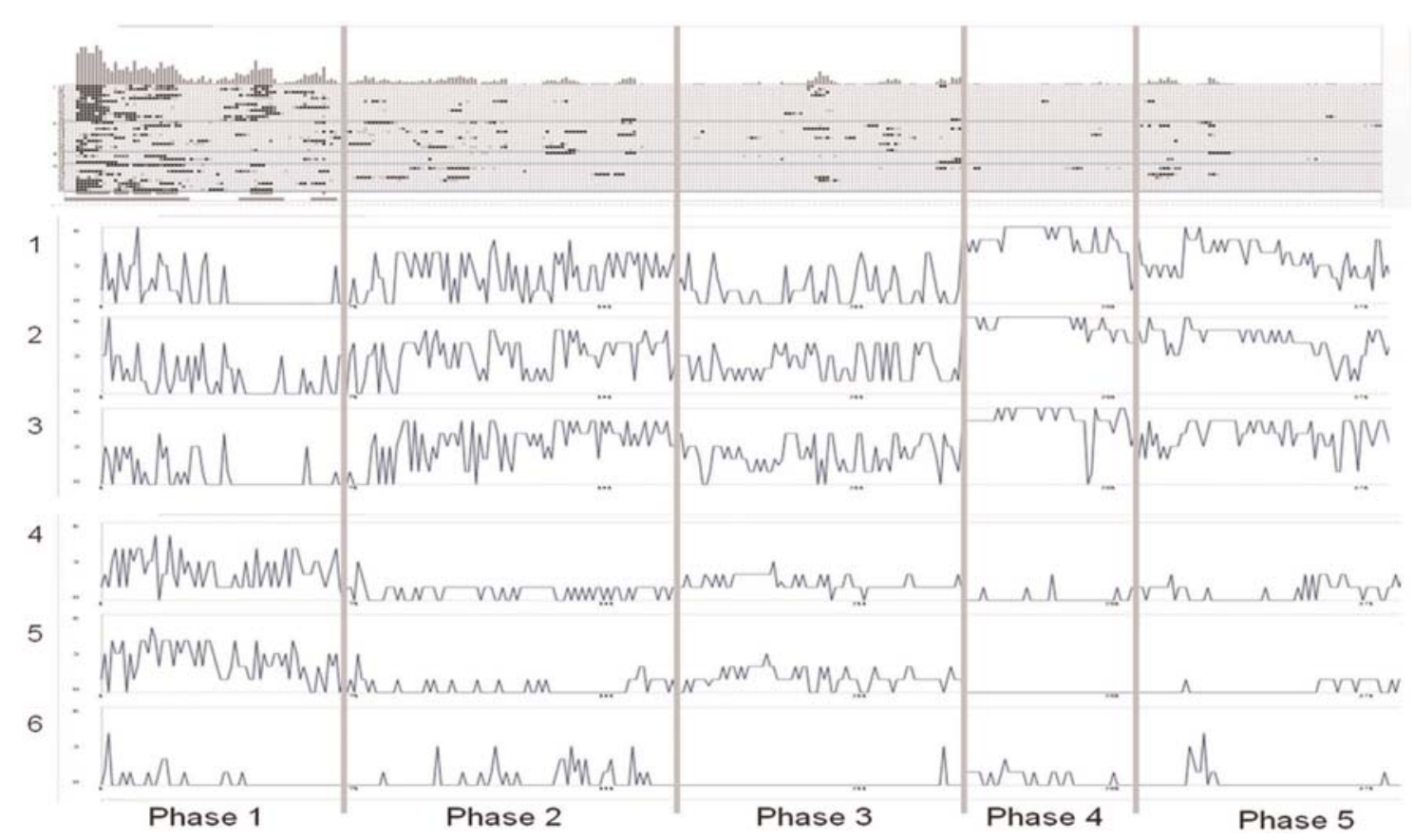

Figure 2 Top section: complexity resonance diagram; bottom section: the raw values for items 1-6: (1) I felt vulnerable today; (2) Today I was really troubled by feelings of worthlessness; (3) I felt lonely today; (4) I think that I can now behave as I would like to; (5) Today I can look to the future with confidence; (6) Today I acted in a way liable to harm myself and/or likely to put myself in danger (suicidal tendency). 
reported her husband to the police. The police referred her to an advisory centre, which, since that time and with consultation of a lawyer, has supported her in the divorce process and the clarification of legal questions. Because a first application for a disability pension was turned down by the Swiss Disability Insurance, Ursula lives on welfare, with her daughter from her first marriage, who is soon to come of age. She cannot at this time pay back the large debts that she inherited from her first marriage. One year ago, she lost her slot in welfare's re-employment programme, because it had instituted minimal part-time work of 50 per cent, which she cannot guarantee due to her physical complaints. As a consequence, the department of social services has increased the pressure and does not want to support anyone who, in the long term, cannot be integrated into the labour market. With the support of an advisor and a lawyer, Ursula has submitted a second application for a disability pension. She has been seeing a therapist for six months due to severe depression and has recently started taking psychopharmacological drugs.

\section{Analysis of real-time monitoring (RTM) data}

In Figure 2, the dynamic course of the one-year period of observation of Ursula Vogel as represented in the RTM data is shown. The interpretation of the data goes together with the information drawn out of the biographical and reflecting interviews and has to be learned like the interpretation of an electro-encephalogram, for example. We cannot take the reader into the process of learning to 'read' the data here. We just can demonstrate and describe what we can see in this kind of data because we have learned to read it. So, please follow our description or guidance through this kind of data. (i) The RTM data show high dynamics across the entire examination time period of one year. (ii) As the complexity resonance diagram at the top of the diagram shows, phase 1 is marked by a cascade of critical fluctuations. How can we see that? The $x$-axis in the diagram shows the time dimension divided into days; on the $y$-axis are the items. The grey and black dots indicate significant intensities (complexity measures) on the items (grey dots: 0.05 level of significance; black dots: 0.01 level of significance). In the histogram at the very top, the dots are shown added up, so that the phases with high critical instability and their intensity are visible. (iii) The analysis of the raw data on the selected items suggests a transition to a non-depressive pattern in phase 1 . And so, despite fluctuations, there are relatively high values on the items on confidence and feeling of competence, and the raw values on the items on suicidal tendency, vulnerability, loneliness and feeling of being worthless sink to zero. (iv) This development in phase 1 is radically interrupted after about two and a half months by what we call a 'negative escalation', which is expressed in the data through a reversal of the values compared to phase 1: the indicators for depression including 
suicidality are high during this phase on average, those of confidence low. (v) The course so far and its further deployment reveal dynamics of oscillation between two structural patterns-relapse to depressive patterns (phase 4) and careful stabilisation (phase 3 and moderate phase 5). Here, it is noticeable, first, that the raw values on the items on feelings of vulnerability, loneliness, worthlessness and suicidal tendency remain dynamic, except in phase 4 , in which the depressive pattern takes hold. Second, it is discernible that the raw values on the items on confidence and feeling of competence increase only slightly after the negative escalation in phase 2. Based on RTM, therefore, a course becomes visible, at the start of which there is a change of pattern and which, however, is interrupted later by a negative escalation, succeeded by oscillation between relapse and careful stabilisation, but stabilising on a relatively poor level in phase 5. As will be shown in the following, the course of these dynamics as represented in the RTM data can be understood through the reconstruction of the structural patterns in Ursula's life conduct system and the way she is integrated into this society. The biographical interview therefore is needed as well as the reflecting interviews in view of the current dynamics. Once again, we wanted to study the interplay of individual and social processes and stated theoretically that these processes are coupled structurally, which means that they are prerequisite for each other, which means that the reconstruction gives an explanation for why Urusla, in this case, in her current dynamics, switches between the two patterns described above.

\section{Reconstruction of the problem genesis and dynamics}

First, it has to be stated that what we present here in the form of a narrative is the result of a careful analysis and reconstruction of the biographical and reflecting interviews. We cannot take the reader into the analysis here, but only can present the result of the analysis that explains the dynamics documented in the RTM data above. In orde to understand the current dynamics, we have to understand the amin patterns and how they came into existence. In all our cases and despite our original intention, this led us back to the beginning of the life conduct systems, that is, to the childhood.

Ursula's life conduct system in childhood in Venezuela is characterised by a socially determined tension between tradition and the modern age, materialised in different integration challenges and options of the action systems that are relevant for socialisation in this phase of life. Ursula Vogel was born in rural structures to a very conservative religious family with rigid values and traditional gender roles. But, in the context of school, due to the excellent fit of the integration demands there and Ursula's thirst for knowledge and her cognitive resources, future options opened up that went beyond her family's horizon of experience. The 
prospects of escaping from the traditional woman's role planned for her in the religious village community by studying in the city and by making an autonomous and modern life for herself, very early - thanks to the competence and meaning that she experienced in the school system-became a powerful emotional driver and thus the dominant attractor in her life conduct system. This development was supported by her integration into a peer group of likeminded girlfriends at school. Only once, she had successfully graduated from school, when her parents forbade Ursula Vogel from accepting her hard-won scholarship for college in the city did the already underlying social tension between traditional and modern life break out and develop into her first experience of failure, connected with a socially structured outer and inner conflict that was her first realisation of her dependency on her parents and thus also the limits of her autonomy. What become visible here are, first, the discrepancy between her life plan and the lack of 'capabilities' to realise it (Sen, 2008) due to her lacking capital (in the sense of Bourdieu, 1983) and, second, the social-structurally determined intra-psychic conflict due to habitus formation (Bourdieu, 1989) in the two action systems having contradictory integration demands and options in the field of tension between traditional and modern life. Against this background, Ursula's strategy for resolving this conflict also becomes visible-namely her persistent search for socially acceptable forms of realising her modern outline of life, under the condition of socially very limited availability of resources. This reveals the central structuring of Ursula's life conduct system up to the present: the tension between the attractor of an autonomous, modern outline of life and the experience of limited chances of realising it. This attractor and the tension caused by him direct her activities that will lead her to migration. Her limited resources and her habitualised strategies together with the specific integration modalities that she will find and create in Switzerland lead to to an increasingly more traumatic reproduction of always the same psychosocial structural pattern, connected with failures and a dramatic narrowing of real conduct of life options.

Upon this background, Ursula's decision to migrate to relatives abroad and to marry a Swiss man can be read as a form of putting her modern outline of life into practice. What she could not see in her youthful naivety was that, with this strategy, she was not taking the first step, as she supposed, into modern life, but, instead, and on the contrary, was reproducing the previous problem pattern in her life conduct system. For, due to her traditionally shaped gender habitus and limited capital in Bourdieu's sense, she was really predestined to become integrated in Switzerland in a highly dependent position on a husband who was precisely not looking for a modern woman, but rather a traditional woman to serve him. The marriage was, for this reason, from the very start, characterised by tension due to asymmetrical expectations and power structures in favour of her husband, who, instead of supporting her in her wish for higher education, 
demanded that she contribute to the family income. She went along with this in this social figuration for as long as she was able to retain the hope that, one day, she could study. This reveals a further strategy for dealing with the tension described above: holding on to the attractor of an autonomous modern life while actively ignoring how limited the chances of realisation are in reality by following the chosen path. For the reproduction of the psycho-social structural pattern, this is a highly functional strategy of repression, which, however, causes tension subliminally and then falls apart, because she can no longer block out the impossibility of realising her life plan within the social figuration concerned. This was the case, when, in analogy to her parents forbidding her to go to college, she realised after the birth of her daughter that her husband had abused her trust and taken out loans in her name. So, she not only had nothing left of her income savings for her university studies, but also was now in heavy debt. The reproduction of her problem dynamics is evident, but there is an important difference, however: whereas, before, she could externalise the reasons for the failure by ascribing it to her parents, this time, she was herself involved in the failure due to her naive trust and behaviour. This activated feelings of guilt, which she immediately repressed, however, in accordance with her strategy for dealing with things. Additionally, through the consequences of leaving her husband, her actual chances of realising her life plans became once again massively reduced. For now, she had heavy debt, responsibility for her daughter and very limited education options in her position as an immigrant.

But, instead of dealing with this reality, she repeated the structural pattern a third time: she worked hard to pay off her debts, sent her daughter to Venezuela, fell in love and married again, despite her own reservations when pressured by both families. Once again, tension produced by asymmetrical expectations was embedded in the relationship from the very startbut, this time, with the tragic consequence that the tension was vented in violent form. Due to her injuries, Ursula now saw her central resource for realising her life plans threatened: her capacity for work. With her tactic of repression, she, of course, at first played down her threatening physical complaints, which, in addition to her social isolation through her husband, meant that she herself contributed to receiving inadequate treatment and to the chronification of her symptoms. This strategy understandably enough broke down when she lost her job due to her physical condition. And, because the old strategy no longer worked in the face of her hopelessness due to losing her ability to work, a new pattern became activated in her psychic potential landscape: depression. Only after that did she succeed, with the help of the advisory centre, in separating from her second husband and reshaping her life conduct system through integration into social services and a re-employment programme, allowing her to bring her daughter back to Switzerland, to ensure her livelihood and to develop at least fragile psycho-social stabilisation. By taking 
recourse to her old strategy, she once again 'settled' and found a certain meaning in life in raising her daughter, in the re-employment programme and in her hobbies. This stabilisation was fragile, because-under highly precarious chances of realisation due to external and inner limitationsshe was again clinging desperately to her plan to go to university and thus once again reproducing the psycho-social structural pattern. It is not surprising that this fragile stabilisation fell apart and that Ursula went into a deep depression when she was taken out of the re-employment programme.

In sum, it can be established that the real chances of realisation of fulfilling her plan for a modern life became massively decreased through the course of biographical reproduction of always the same structural pattern, interrupted by short crises. And this is what we finally see in the RTM data introduced above. In her psychic potential landscape, there is oscillation between two major cognition/emotion/behaviour patterns. The first pattern reflects her long-year strategy of persistently pursuing her life plan while blocking out the real limitations. The life plan becomes, so to speak, an ideology that is essential to her life and needs to be kept alive opposite reality under all conditions, because only in this way can confrontation with the trauma be avoided. That describes the first avoidance pattern, which, due to the avoidance strategy embedded in it, leads to repeated failure situations that trigger new tensions and reactions from others, such as social workers making pressure in order to 'activate' this client. These triggers activate the traumatic tension between ideology and reality, which, as control parameters, then initiate the order transition into the second pattern. The second pattern, which can be described as 'depression', is characterised by lack of drive/initiative, social withdrawal, loss of self-esteem, fear of the future, loss of a sense of the meaning of life, suicidal tendency and dissociation as shown by the selected RTM items. Just as soon as Ursula recovers a little bit, she shifts into the mode of the first pattern. Both patterns are engergised by the attractor of her life plan, which has changed into a traumatic experience. The data analysis shows that, with increasing reproduction of the psychosocially determined failure spiral very much in the sense of learned helplessness (Seligman, 2004), even little tensions or failure expectations are sufficient to set off an order transition into the depressive/traumatic pattern. The oscillation between the patterns becomes independent and materialises due to the repeated experience of powerlessness in a traumatic loss of control.

It is just like two persons. As soon as I'm down, I try to get up, would like to get up again. And as soon as I'm up, I go down again .... So as soon as I'm up, I get afraid, afraid about how will I get on, what, just a lot of questions: For what? What's the use? Am I worth it? And things like that; that alone is dreadful for me. And I somehow feel that I am satisfied and at the same time sad. It is somehow the feeling that I am not suited to it or something. 
I imagine so many things that I would like to do, but I can't. It is these things simply. And then within myself, at the end it is blocked, and the negative feelings come up again (Ursula Vogel, speaking about phase 3).

If we re-examine the RTM data explained above upon the background of the reconstruction of the problem genesis and dynamics described and also include the data analysis of the reflecting interviews, a rather sobering picture is revealed. In counselling and therapy, in a first step, there was success in creating a situation in which Ursula no longer saw her existence as directly threatened. This included: resolving conflicts with the social services department, re-opening the discussion concerning a disability pension, building a sound therapeutic alliance and prescribing psychopharmacological drugs. With this, at the start of the period being studied, the necessary stability conditions for a change in structure were in place so that, in phase 1, a therapy-supported order transition in a new cognition/ emotion/behaviour pattern became possible. This process was continued in phases 3 and 5, which, despite clear stabilisation tendencies, are characterised by persisting fluctuations and brief relapses into the problem pattern. These fluctuations, just like the relapses in phases 2 and 4, not only indicate the very fragile nature of the process, but also make it clear that the new cognition/emotion/behaviour pattern could not become stabilised during the period being studied.

With the two following additional cases, we briefly want to illustrate again that the RTM data together with the interviews enable us to reconstruct the relatedness of social and psychic processes and open a door to the understanding of the dynamics of this interplay as well as to the patterns in the psychic system, which provides at the same time precious information for intervention.

\section{Astrid Weber}

The RTM data for Astrid Weber show completely different dynamics and structural patterns from those revealed for Ursula Vogel (see figure 3). Astrid is in no way depressed. Instead, it is noticeable that, with few exceptions, the raw values of items 1-3 are maximal scores. In other words, Astrid almost always looks to the future with confidence during the period of nearly a year, she always has life under maximal control and she never has self-esteem problems. But this cannot be-not for people who have no existential problems or trauma and certainly not for Astrid, as reconstruction of her life conduct system based on the biographical and reflecting interviews shows. What this example really shows is that structural patterns in her life conduct system are mirrored directly in the RTM data. Here, we see a pattern of whitewashing, or glossing over, that Astrid learned in a childhood that was marked by violence. She reproduces 


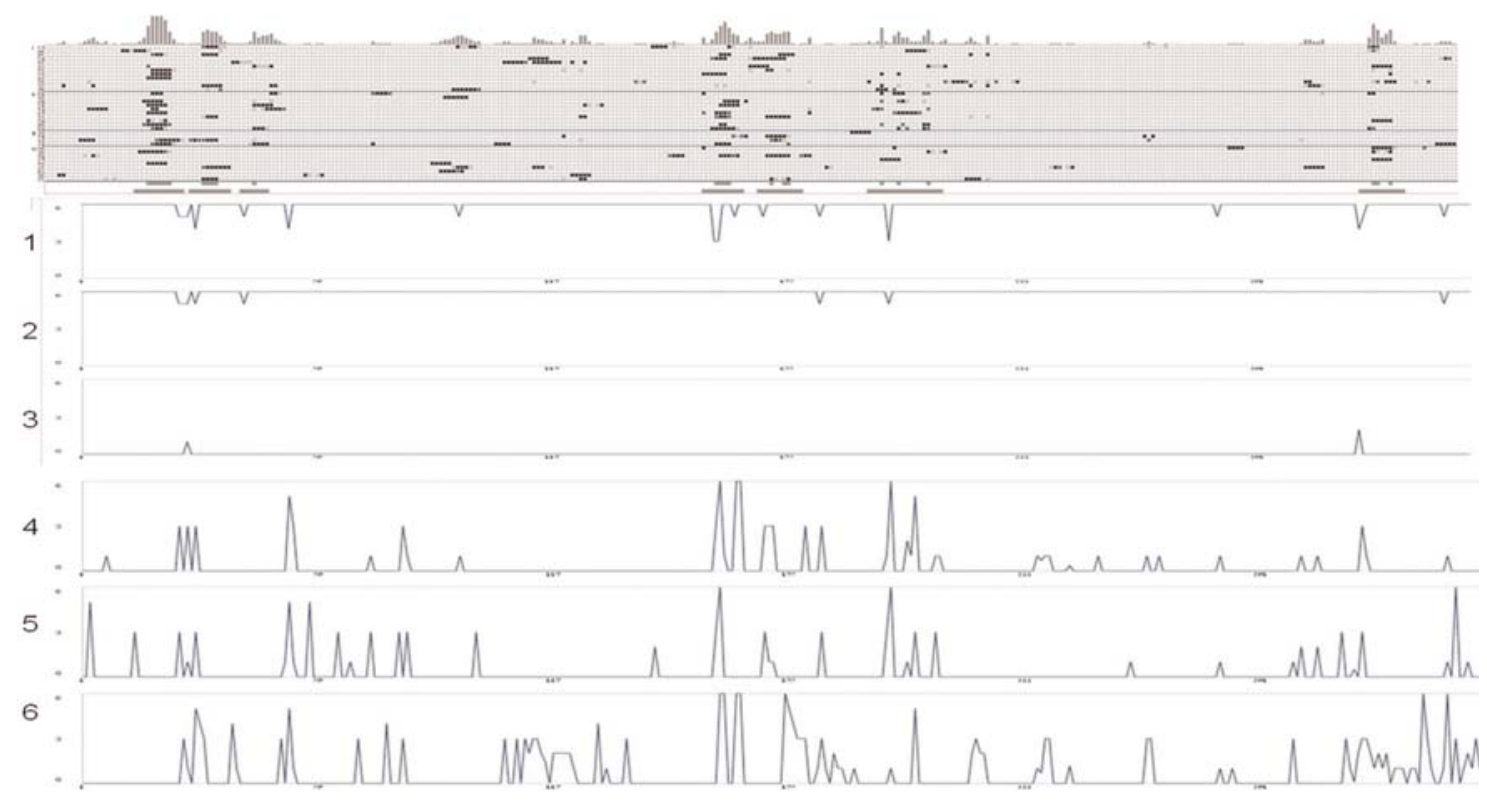

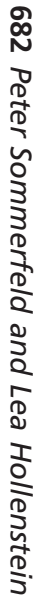

Figure 3 Top section: complexity resonance diagram; bottom section: the raw values for the following items: (1) Today I can look to the future with confidence; (2) Today I felt that I had my life under control; (3) Today I was really troubled by feelings of worthlessness; (4) I felt afraid today; (5) I felt angry today; (6) Last night I had difficulty sleeping/I had bad dreams. 
this whitewashing pattern for many years in a violent marriage and, in the current dynamics, this is highly dangerous, because she completely blocks out the increased danger from her ex-husband after they separate. Nonetheless, the RTM data reveal the tension that accompanies this danger. This is indicated clearly by the critical fluctuations in the complexity resonance diagram and the raw values on items $4-6$, starting with the confrontation with the separation proceedings close to the beginning of the observation period and about mid-course when the perpetrator (her ex-husband) is released from prison. Only with the delayed intervention by the school regarding the children and owing to counselling does Astrid learn to interrupt the conflict dynamics through distanced reserve. When her ex-husband does not comply with the court order to move away and no sustainable solution is in sight, the tensions increase again near the end of the time period being studied.

\section{Gabi Winkler}

The course of Gabi Winkler's data shows high dynamics up to the end, especially at the level of the factor on negative emotionality (see figure 4). As a child, Gabi, too, was the victim of violence by her father. At the same time, her father was her only principal care-giver, which made her dependent on him. Also, Gabi reproduced in her marriage, largely structurally analogously, the violence experienced in childhood. We are dealing here with problematic structural patterns in her life conduct system that Gabi reproduced for years and that, for this reason, became deeply embedded in her psychic potential landscape. In the foreground here is incomplete development of ego autonomy and self-esteem, intensified by the presence of her twin sister, to whom she is close. This incomplete development makes her dependent on receiving recognition from others, especially her father and later her husband. It should be emphasised that the relationship is one of mutual dependency. This is shown by, among other things, the fact that, as a woman who is well integrated in the labour system in Switzerland, she seeks an Asian man, who becomes integrated in Switzerland in a position that is inferior and dependent on her. This describes in brief the circle of tension that again and again erupts into power games, in which he tries to push through his interests in dynamics of shifting strategies: recognition, debasement, violence, taking the role of victim. All of this, due to Gabi's fear of violence and due to her dependency on recognition, makes Gabi highly vulnerable to being involved in the reproduction of the power structural pattern. These dynamics start up once again when the protective measures decreed following a police operation come to an end and when her husband's supervised visitation rights with their son begin (phase of strong critical fluctuations in RTM chart above). In place of physical violence, her husband now 


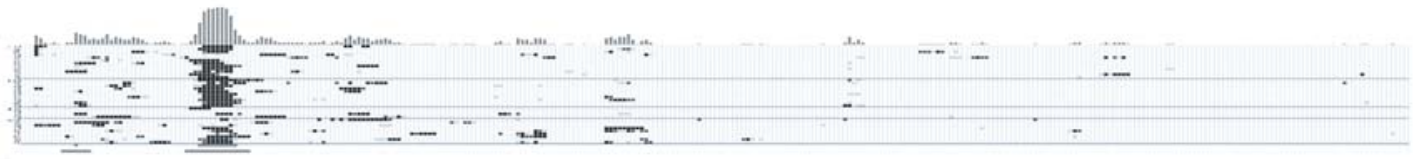
...

w

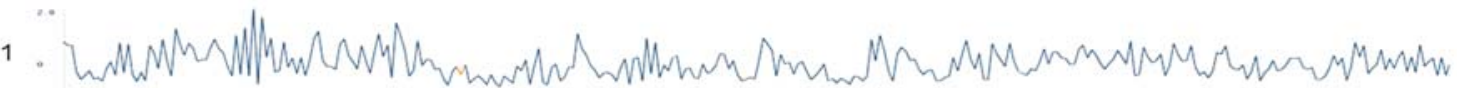
4.

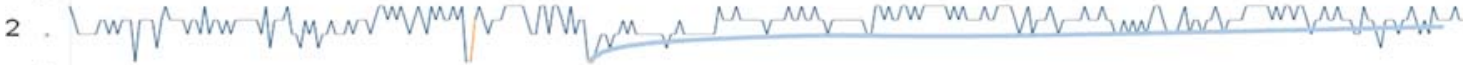

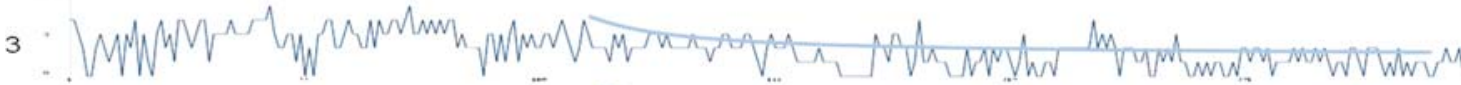

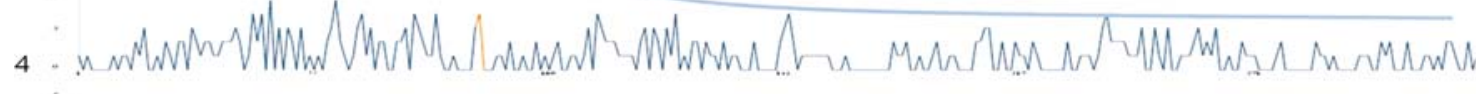
5 ,

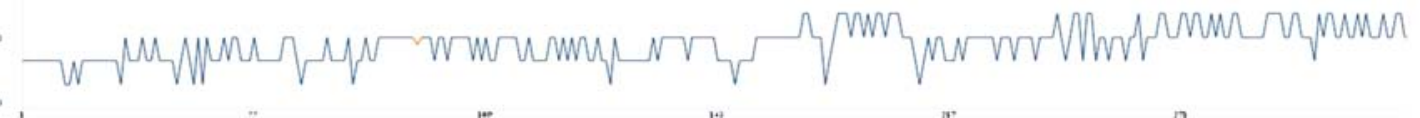

Figure 4 Top section: complexity resonance diagram; bottom section: the raw values for the following factors and items: (1) Factor: negative emotionality; (2) Today I felt that the atmosphere in my private environment was full of conflict/very relaxed; (3) Today I felt dependent on others; (4) Today I was really troubled by feelings of worthlessness; (5) I think that I can now behave as I would like to. 
threatens to kidnap her son, for which it is very difficult to bring a charge against somebody. Alongside that, Gabi's course shows cautious development of autonomy and self-esteem that begins with her escape from violence and is later supported through therapy, but it is again and again interrupted by the power dynamics described. In this connection, the cascade of critical fluctuations visible in the complexity resonance diagram above is important. It can be traced to the decision by the immigration authorities not to renew her husband's residency permit, which gives Gabi, for the first time, prospects of a truly autonomous life outside of these dynamics. This development is also reflected in items $2-4$, after Gabi distanced herself more from her twin sister due to a conflict, and it is distinctly recognizable in the clearly positive direction in item 5. Contributing to this were therapy and also work, where she can apply her resources and experience self-efficacy, and because employment gives her a feeling of autonomy and self-esteem.

\section{Discussion}

The theoretical approach and the corresponding methodology introduced in this paper in our view constitute a step in digging deeper into the complex and dynamic interface of interrelated individual and social processes that social work deals with. As has been tried to show above, the mix of quantitative and qualitative methods enables us to obtain a realistic view of the dynamics that a specific individual is experiencing and to create a plausible picture of the main individual patterns conditioned by the concrete social living conditions explaining the current dynamics. The forms of integration in social action systems realised can be described and related to the individual cognition/emotion/behaviour patterns as well as to the societal and cultural macro structure. However, this is still just a beginning. There are several tests to be conducted and more experience in using this methodology has to be gained to know its real quality and weaknesses.

But we also wish to present our methodological approach for discussion with regard to the world of practice. The practice of social work is confronted like hardly any other profession with the complexity and dynamics of the human conduct of life. In our research work, we have to realise again and again that the temporal dynamics and complexity of cases are not captured sufficiently (Sommerfeld et al., 2008). The example of 'Ursula Vogel' shows that, at the case level, important action options are unrecognised and thus also remain unutilised and even that certain insufficiently complex practices and programmes, as in this case, can result in harmful effects (such as exclusion from the re-employment programme). For this reason, the question arises as to whether and how the complexity of cases can be adequately captured in practice and whether the methodology generated here for research can be used for that purpose. The 'reflecting interviews' 
that we developed come very close to counselling methods. RTM is used in Germany in clinical settings (e.g. for counselling with anxiety disorders). Combining the reflecting interviews with the data from RTM has proved to be a very fruitful way to get closer to the structural patterns behind the case dynamics and to continuously improve the quality of the picture. In our case, we built the foundation for this via the biographical approach. Biography work is also a common method in social work (Hölzle and Jansen, 2009). When we intervene in existential processes of a fellow citizen, would it not make sense, or should it not even be mandatory, that we do so on the basis of a serious and well-founded understanding of the real complexity and dynamics of the case? But how could that be done in the kind of practice that is mostly found today and that has been trimmed for immediate efficiency?

In conclusion, and to close the circle, we refer to the realist evaluation paradigm that we mentioned at the outset with the quotation from Kazi. Based on the explanations outlined above, it should have become clear that our approach is very close to that paradigm. In an earlier work (Sommerfeld et al., 2005), we described, from a professional development perspective, that evaluation through research is a necessary and important building stone for the further development of the profession of social work and that, for this, single case designs are the approach of choice, because professional work adjusts to single cases and because we can learn from data on the single cases, in connection with an explanation of how an effect is produced and cannot learn from highly compacted black-box evaluations that are associated with randomised controlled trials. Like Kazi, we assume that data that are generated directly in practice and are used by practitioners in their daily work are important for the building of a professional knowledge base. We also assume that, for this, cyclical processes are needed and that, through the use of data on single cases generated in practice, research and evaluation play an important role in the building of that professional knowledge base (Gredig and Sommerfeld, 2008). We wonder, and present the issue for discussion, whether, with the theory of life conduct systems, we cannot more precisely capture the 'context' and whether the perspective on the dynamics of the processes is not a further-reaching perspective at human life than the concept of 'mechanisms'. Here, we do not intend to contrast the two; instead, we understand our work as a contribution that goes in the same direction, but using other theoretical and empirical means. This common direction seems to us to be forward-looking, and it expands the discourse on different concepts and methods.

\section{Acknowledgements}

The project has been funded by the Swiss National Science Foundation and by the Förderverein Fachhochschule Nordwestschweiz Solothurn (Friends 
of the University of Applied Sciences Northwestern Switzerland Solothurn).

\section{References}

Bourdieu, P. (1983) 'Forms of capital', in J. G. Richardson (ed.), Handbook of Theory and Research for the Sociology of Education, New York, Greenwood Press.

Bourdieu, P. (1989) Die feinen Unterschiede: Kritik der gesellschaftlichen Urteilskraft [Distinction: A Social Critique of Judgement], Frankfurt a.M., Suhrkamp.

Bourgett, J. and Brülle, H. (2000), 'Überlebenssysteme in Konkurrenz: Start einer notwendigen Debatte' ['Survival systems in competition: Start a necessary debate'], in S. Müller, H. Sünker, T. Olk and K. Böllert (eds), Gesellschaftliche Bedingungen und professionelle Perspektiven [Social Conditions and Professional Perspectives], Neuwied/ Kriftel, Luchterhand.

De Shazer, S. (1991) Putting Difference to Work, New York, Norton.

Elias, N. (1978) What Is Sociology, New York, Columbia University Press.

Elias, N. (1995) 'Figuration', in B. Schäfers (ed.), Grundbegriffe der Soziologie [Basic Sociology], Opladen Leske + Budrich.

Fischer, G. and Riedesser, P. (2003) Lehrbuch der Psychotraumatologie [Textbook of Psycho-Traumatology], München/Basel, Ernst Reinhardt Verlag.

Gredig, D. and Sommerfeld, P. (2008) 'New proposals for generating and exploiting solution-oriented knowledge', Research on Social Work Practice, 18(4), ppp. 292-300.

Greene, J. C., Haight, W. L. and Sommerfeld, P. (2010) 'Mixing methods in social work research', in K. Briar-Lawson, J. Orme, R. Ruckdeschel and I. Shaw (eds), The SAGE Handbook of Social Work Research, Los Angeles, London, New Delhi, Singapore, Washington, Sage.

Haken, H. (1990) Synergetik: Eine Einführung [Synergetics: An Introduction], Berlin, Springer.

Haken, H. and Schiepek, G. (2006) Synergetik in der Psychologie: Selbstorganisation verstehen und gestalten [Synergetics in Psychology: Understanding Self-Organization and Design], Göttingen, Hogrefe.

Hölzle, C. and Jansen, I. (eds) (2009) Ressourcenorientierte Biografiearbeit: GrundlagenZielgruppen-Kreative Methoden [Resource-Oriented Biographical Work: Basic Target-Group-Creative Methods], Wiesbaden, VS Verlag für Sozialwissenschaften.

Kazi, M. A. F. (2003) 'Realist evaluation for practice', British Journal of Social Work, 33, ppp. 803-18.

Onken, S. J., Dumont, J. M., Ridgway, P., Dorman, D. H. and Ralph, R. O. (2002) Mental Health Recovery: What Helps and What Hinders, New York, Columbia University.

Dumont, J. M., Ridgway, P., Onken, S. J., Dornan, D. H. and Ralph, R. O. (2005) Mental health recovery: What helps and what hinders? A national research project for the development of recovery facilitating system performance indicators. Phase II technical report: Development of the recovery oriented system indicators (ROSI) measures to advance mental health system transformation. Alexandria, VA: National Technical Assistance Center for State Mental Health Planning.

Pawson, R. and Tilley, N. (1997) Realistic Evaluation, London, Sage Publications.

Schiepek, G., Weihrauch, S., Eckert, H., Trump, T., Droste, S., Picht, A. and Spreckelsen, C. (2003) 'Datenbasiertes Real-Time Monitoring als Grundlage einer gezielten 
Erfassung von Gehirnzuständen im psychotherapeutischen Prozess' ['Data-Based Real-Time Monitoring as a basis for targeted detection of brain states in the psychotherapeutic process'], in G. Schiepek (ed.), Neurobiologie der Psychotherapie [Neurobiology of Psychotherapy], Stuttgart, Schattauer.

Seligman, M. E. P. (2004) Erlernte Hilflosigkeit [Learned Helplessness], Weinheim, Beltz.

Sen, A. K. (2008) Commodities and Capabilities, New Delhi, Oxford University Press.

Sommerfeld, P., Calzaferri, R. and Hollenstein, L. (2008) 'Die Dynamiken von Integration und Ausschluss: Zur Erfassung und Bearbeitung von Komplexität in der Sozialen Arbeit' ['The dynamics of inclusion and exclusion: For registration and processing complexity in social work'], in C. Conrad and L. von Mandach (eds), Auf der Kippe: Integration und Ausschluss in Sozialhilfe und Sozialpolitik [In the Edge: Integration and Exclusion in Social Assistance and Social Policy], Zürich, Seismo Verlag.

Sommerfeld, P., Calzaferri, R., Hollenstein, L. and Schiepek, G. (2005) 'Real-time monitoring: New methods for evidence-based social work', in P. Sommerfeld (ed.), Evidence-Based Social Work: Towards a New Professionalism?, Bern, Frankfurt, New York, etc., Peter Lang Verlag.

Strauss, A. L. and Corbin, J. (1990) Basics of Qualitative Research: Grounded Theory Procedures and Techniques, Newbury Park, Sage.

Völter, B., Dausien, B., Lutz, H. and Rosenthal, G. (eds) (2009) Biographieforschung im Diskurs [Biographical Research in the Discourse], Wiesbaden, VS Verlag für Sozialwissenschaften. 